\title{
AN INTEGRATED MODEL FOR EVALUATING SELF SUSTAINABILITY OF BIO-ENERGY SETTLEMENTS: TECHNOLOGICAL, ECONOMICAL AND SOCIAL ASPECTS
}

\author{
Alessandro Catania A \\ IQR COnsulting \\ Albenga SV, 17031, ITALY
}

\author{
Roberto Revetria \\ Francesca Oliva \\ Lucia Cassettari \\ DIPTEM \\ Genova, 16156, ITALY
}

\begin{abstract}
The proposed paper present a generalized model based on Monte-Carlo simulation able to support the feasibility study by effectively model the production process, the woods groove and the overall logistics. This model can be applied to quantitatively identify cost and benefits for an integrated biomass energetic district and identify, at the same time, potential and pitfalls that usually reduce the success of an ecologic initiative. A case study implementing the proposed methodology is presented and discussed.
\end{abstract}

\section{INTRODUCTION}

The main subject of the proposed analysis is the feasibility study of biomass energetic utilization. The territorial planning of such utilization presupposes correlation between the supply of biomass, structure and localization of involved business, potential centre of storage and transformation and the related sources of supply and consumptions. The introduction of high efficiency biomass heating systems has opened new prospective for the energetic utilization of wood with systems situated near the user in woody areas. The plant location is optimized through the searching of the best site inside wood high productive areas with a convenient network of forests paths, satisfactory presence of woody business and an easy linking with the grid. The economic project is realized with maximum scientific severity considering the environmental impact, social and economic consequences and the influence of public facilities. Biomass heating offers a number of compelling advantages, both for the system owner and, in the case of district heating systems, for the local community. It can supplant expensive conventional energy sources such as fossil fuels and electricity with local biomass resources, which is often available at little or no cost as waste or low-value by-products from various industries (e.g. forestry and agriculture) (Risoffi 2000). In doing so, overall levels of pollution and greenhouse gases are re- duced, the purchaser is insulated from fossil fuel price shocks, and local jobs are created in the collection, preparation, and delivery of the feedstock.

Biomass heating systems tend to have higher initial costs than conventional fossil fuel burning systems. Furthermore, the quality of biomass feedstock is highly variable in comparison with the relatively standardized commercially available fossil fuels. Feedstock delivery, storage, and handling are more complex as a result, and often more physical space is required. All these factors require a high level of operator involvement and diligence.

Therefore, biomass-heating systems are most attractive where conventional energy costs are high and biomass feedstock costs are low. This occurs when electricity or some other costly form of energy are used for space and water heating; and biomass residues are available onsite or nearby at zero cost or, if there is a disposal fee for the biomass residues, at a discount.

\section{BACKGROUND}

Community energy systems can make use of a biomass heating, a district heating system, a wind power system and a hydroelectric system rationally integrated to service clusters of building or even an entire community. These energy systems are considered renewable because utilise sources of energy inexhaustible.

Such community energy systems exploiting the natural resource of a country (wind, river, forest) in sustainable way can provide space heating, heating of ventilation way, water heating, process heat and electrical demands. These can be supplied to individuals such as institutional (hospitals, schools, sports complexes), commercial (offices, warehouses, stores), industrial buildings ( in the case that we'll analyze sawmills) and residential (apartments). They can also provide heat and electricity to individuals' homes especially if the houses are newly constructed and in groups. 


\section{Catania et al.}

Our model is composed by a series of medium city that are dipped in an area very rich of natural resources: there are numerous woods divided in three yards characterized by different intensity of wood cutting. These forests supply wood at the biomass heating systems and at the local sawmills that can provide waste wood at same biomass heating system. In fact they utilize a fraction of the harvested log (bark, sawdust, shavings, and chip from wood) that can not be cut to dimensional lumber, but that can be transformed into woodchips to feed combustion chambers. A fraction of the heat requirements of the citizens are satisfied by the biomass systems, the residual part is supplied by conventional fuel heating system while the electricity demands by the wind power system and hydroelectric productions. These electric productions are connected with the national grid. The wind power system plant is situated in the near hills profiting of the windy area, while the hydroelectric plant utilizes the potential energy of two river's water, and the flow derivable during the year is in function of rainfall regime. The activities of the sawmills and other plants create local job and increase the amount of population. So we have an integrated system with mutual connections because a larger population consume more energy and this event influences the quantity of natural resources necessary for a larger energy productions. At the same time the exploitation of natural resources must be managed in sustainable way: in fact, felling of trees and intensity of taking wood are regulated by cut plans that assume particular importance because take in consideration the vegetative cycle. This permits the natural re growth of tree after the cut and to have woods well-kept that furnish marketable wood.

\section{MODEL DESCRIPTION}

The principal purpose of the proposed analysis is to design a model of this integrated energetic production system through few steps:

- Disassemble the model in different unit

- Define what input and output describe the different unit

- Establish, in all the unity that compose the model, which stochastic input have influence on results of output

- Assign a probability distribution to inputs

- Study the behaviour of output

This procedure generates various scenarios characterized by different productions of heat and electricity in consequence of natural resource parameters that change. Such model can be subdivided into six units:

\subsection{UNIT- Wind power system}

- Input: wind that is somewhat related to the amount of rain.

- Specification: nominal power, diameter, number and position of turbine, total power of plant, altitude of power, length of crest, index of electric production, standard of wind direction

- Output: electric production

\subsection{UNIT- Hydroelectric}

Is composed by two geodetic step

- Input: amount of rain, flow of basin

- Specification: beneath area of basin, minimum life de-flow, altitude of geodetic step, nominal power of plant, number of working hours at nominal power,

- Output: electric production

\subsection{UNIT-Sawmills}

There are few sawmills of small dimension with production approximately of $40.000 \mathrm{~m}^{3}$ and 20 operators

- Input: amount of lumber

- Specification: various component of plant

- Output: operator, electric requirements, waste wood

\subsection{UNIT-City}

There are groups of medium town structurally well connected with a valid road system

- Input: sawmills operators

- Specification: number of initial resident

- Output: number of resident number, electrical and heating demand

\subsection{UNIT- Woods}

- Input: amount of rain, rate of trees growth

- Specification: medium thermal power, intensity of cuts (cut plan)

- Output: total volume of wood, volume of taking wood

\subsection{UNIT- Biomass heating system}

- Input: heating demand of resident, quantity of wood furnished by local woods and sawmills

- Specification: site conditions (design temperature and degree days, equivalent degree days for domestic hot water), waste heat recovery, bio- 


\section{Catania et al.}

mass combustion system, peak load heating system, energy mix determination,

- Output: biomass requirements

The chain of influence of the principal parameters is explained in figure 1 .

The design model takes in consideration only the inputs that influence strongly the results of the system and have a wide range of change. The unit more important and critical for the system is " woods " because the running of system depends on it. These forests assure raw materials for the sawmills and biomass heating system, the increase of rate of trees growth produces greater volume of commission and could satisfy on one side a greater demand for lumber of sawmills (it could be due to a greater requirements of clients) and other side a greater quantity of woods necessary for the biomass heating system to answer to one greater heating demand.

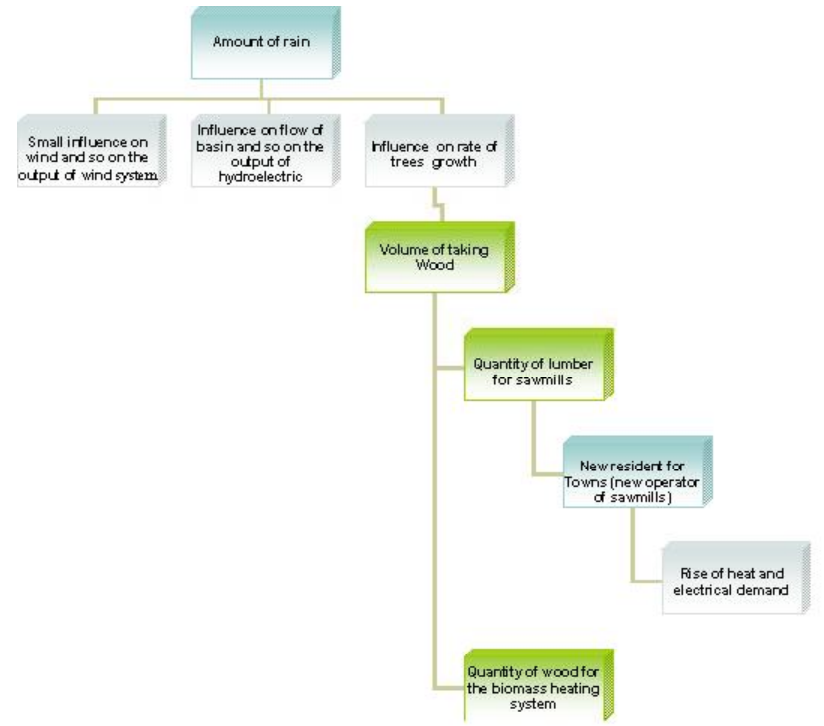

Figure 1: Model State Variables’ Interaction Schema

Our model doesn't consider directly elements that in the reality would influence development of woods:

- Type of cultivation

- Arboreal species

- Government shape

- Fertility of ground and conditions generates them of increase

- Health conditions

- Type of cut

- Organization of the yard

Neither other factors that influence the amount of cutting wood like:
- Technical factors (slope of land, fortuitousness of surface, technology of felling and pull outside wood)

- $\quad$ Forestry factors (type of wood and forestry technique, surface of forest cutting, trees dimension, intensity of cut, accessibility of the forest and direction of wood pull outside)

- Parameters of forest practicability (density, distance )

We have taken in consideration the totally effect of these individual factors dividing the forest in three yard characterized by different sums of factors that together form a cut plan coherent with a sustainable development of forest:

- In the yard A (firewood to burn) we have identify a plan cut that preview the $25 \%$ of the present volume

- In the yard B (firewood from work with thinning) the suitable cut plan indicates the $3 \%$ of present volume

- In the yard $\mathrm{C}$ (firewood from work marketable) we suppose $3 \%$ of present value

The biomass heating system feed his combustion chamber with a mix of supplies;

- Before utilise the wood waste coming from sawmills (this quantity depends from wood work every year)

- After takes $43 \%$ of $3 \%$ of yard C (depends from volume present)

- Then the wood of yard B

- The lacking part from yard A

Biomass heating systems burn organic matter-such as wood, wood chips, agricultural residues or even municipal waste - to generate heat. This heat can be transported and used wherever it is needed - for the ventilation and space heating requirements of buildings or whole communities, or for industrial processes. Biomass heating systems differ from conventional wood-burning stoves and fireplaces in that they typically control the mix of air and fuel in order to maximize efficiency and minimize emissions, and they include a heat distribution system to transport heat from the site of combustion to the heat load. Many biomass-heating systems incorporate a sophisticated automatic fuel handling system. Today, there are thousands of these systems in operation around the world, using a multitude of different types of biomass fuels, or "feedstock". Despite this, much of the general public and many heating professionals are unaware of the benefits of this cost-effective, proven, and reliable source of energy. The recent emphasis on renewable energy resources as replacements for conventional fuels, spurred by concerns about greenhouse gas (GHG) emissions, is caus- 


\section{Catania et al.}

ing a resurgence of interest in biomass heating, where the biomass is harvested in a sustainable manner.

Biomass heating offers a number of compelling advantages, both for the system owner and, in the case of district heating systems, for the local community. It can supplant expensive conventional energy sources such as fossil fuels, because it is often available at little or no cost as waste or low-value by-products from various industries (e.g. forestry and agriculture) (Schlamadinger and Marland 1996). In doing so, overall levels of pollution and greenhouse gases are reduced, the purchaser is insulated from fossil fuel price shocks, and local jobs are created in the collection, preparation, and delivery of the feedstock. In addition, the heat distribution system of the biomass heating plant facilitates the use of waste heat from on-site power generation or thermal processes (i.e. waste heat recovery, or "WHR") and can be extended to service clusters of buildings or even whole communities in a "district energy system".

Biomass heating systems tend to have higher initial costs than conventional fossil fuel burning systems. Furthermore, the quality of biomass feedstock is highly variable in comparison with the relatively standardized commercially available fossil fuels. Feedstock delivery, storage, and handling are more complex as a result, and often more physical space is required. All these factors require a high level of operator involvement and diligence.

Therefore, biomass-heating systems are most attractive where conventional energy costs are high and biomass feedstock costs are low. This occurs when: electricity or some other costly form of energy is used for space and water heating; and biomass residues are available onsite or nearby at zero cost or, if there is a disposal fee for the biomass residues, at a discount. Because of their size and complexity, the use of automated biomass combustion systems is largely limited to the industrial, commercial, institutional and community sectors. They tend to be located in rural and industrial areas, where restrictions on the types of pollutants they emit may be less severe, truck access for feedstock delivery may be in place, feedstockhandling equipment such as loaders may already be available, and the labour and expertise required to operate an industrial type boiler system may be easier to find.

Biomass combustion systems are often well suited to industrial process loads. Many industrial process loads have constant heat requirements and biomass heating systems operate most efficiently, and with the fewest operational challenges, when they supply a relatively constant quantity of heat, near their rated capacity, throughout the year. This also maximizes fuel savings by displacing a large amount of expensive conventional fuel, justifying the higher initial capital and ongoing labour costs of the system. (Corgnati 1999)
In the implemented model the principal factor that seem modify more all energetic productions is the rain as show in previous diagram. His influence can be noticed in many variable that we have identified in the phase of simulation (it comprises also economic appraisal) (Brun and Furlan 2000).

\section{SIMULATION}

This section describes which variables (input parameters) are uncertain and replaces them with appropriate random variables. (Wang., Weller, and Hanna 2005) The uncertain variables are:

- Rainy

- Selling prices of three yards

- Selling prices of sawmills

- Value of KWh

- Prices of green certificated

- Expenses of maintenance for hydroelectric and wind power system

Modifying their values at every run we have observed the changing behaviour of 8 output:

- Woods volumes

- Number of resident

- Total electrical consumptions

- Hydroelectric productions

- Wind power system productions

- Profits of three yard

- Profits of sawmills

- Residual amortization of hydroelectric and wind power system

The program that we have used allows entering numerical data (input parameters) relevant to the problem and formulas that specify the relationship between these values and other quantities of interest into the cell of electronic table. When the input parameters are changed, the values of other quantities depending on these parameters are automatically recalculated and displayed, allowing playing an unlimited number of what-if games with the spreadsheet.

Each parameter must be replaced by a random variable represents the relative likelihood for the parameter's possible values (we have used triangular and normal distribution because we don't have enough data to enable us to select confidently from among several distribution). (Bruzzone, Giribone, and Revetria 1999)

Once a distribution has been selected, we must compute the parameters of the distribution to use when generating random variables. The parameters that must be computed depend on the distribution.

In the simulation we have repeated the experiment several times and used statistical methods to estimate the mean from the data produced. The model involves ran- 


\section{Catania et al.}

dom variables and a single replication is normally too variable to allow reliable conclusions to be drawn. One might be suspicious to evidence the changes of output. Each initial input corresponds to a specific distribution for the resulting outputs. (Banks, Carson, and Nelson 1996)

Each time the spreadsheet is recalculated, a new observation is produced using the newly generated random variable for the uncertain variables. This can be a way to determine how particular financial and atmospheric events produce particular outcomes in a district energy system

With these methods we can construct different scenarios changing for example the limits and the maximum of triangular distribution

The spreadsheet model provides a representation of the energetic production and financial consequences cross 20 years in our district energy system.

\section{IMPLEMENTED MONTE CARLO SIMULATOR: RESULTS}

Statistical simulation methods may be contrasted to conventional numerical discretization methods, which typically are applied to ordinary or partial differential equations that describe some underlying physical or mathematical system.

In many applications of Monte Carlo, the physical process is simulated directly, and there is no need to even write down the differential equations that describe the behaviour of the system. (Anonymous 1991) The only requirement is that the physical (or mathematical) system be described by probability density functions (pdf's). In such way we will assume that the behaviour of a system can be described by pdf's. Once the pdf's are known, the Monte Carlo simulation can proceed by random sampling from the pdf's.

Many simulations are then performed (multiple "trials" or "histories") and the desired result is taken as an average over the number of observations (which may be a single observation or perhaps millions of observations). In many practical applications, one can predict the statistical error (the "variance") in this average result, and hence an estimate of the number of Monte Carlo trials that are needed to achieve a given error.

The goal of the Monte Carlo method is to simulate the physical system by random sampling from these pdf's and by performing the necessary supplementary computations needed to describe the system evolution. In essence, the physics and mathematics are replaced by random sampling of possible states from pdf's that describe the system.

This simple yet elegant sampling rule was first suggested by von Neumann in a letter to Ulam in 1947 (Los Alamos Science, p. 135, June 1987). It is sometimes called the "Golden Rule for Sampling". Since so much use will be made of this result throughout this chapter, we summarize below the steps for sampling by inversion of the cdf:

- $\quad$ Step 1.- Sample a random number $\xi$ from $U[0,1]$

- $\quad$ Step 2.- Equate $\xi$ with the cdf: $F(x)=\xi$

- $\quad$ Step 3.- Invert the cdf and solve for : $\mathrm{x}=\mathrm{F}-1(\xi)$

The implemented simulation model was built on top of an Microsoft ExcelTM File by using Orlando Simulation SimSheet. SimSheet ${ }^{\mathrm{TM}}$ adds simulation capabilities to Microsoft Excel ${ }^{\mathrm{TM}}$ spreadsheets. SimSheets are for planning applications to extend spreadsheet analysis to explore in greater depth the range and likelihood of outcomes. With traditional spreadsheets, a single value is used to represent a range of possible values (i.e. estimated number of units sold for the month, labour expenses for the quarter, etc...).

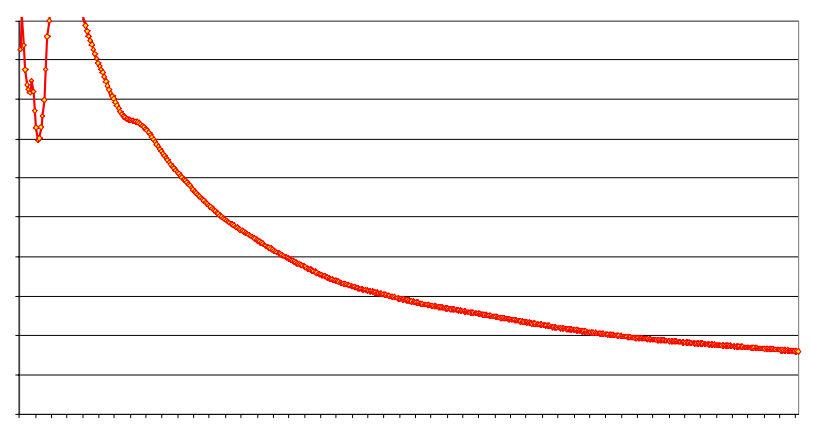

Figure 2: MSpE Time Evolution Analysis

SimSheet ${ }^{\mathrm{TM}}$ provides new functions for Excel that allows estimates, probabilities and ranges for planning variables to be used. A SimSheet ${ }^{\mathrm{TM}}$ run uses statistical sampling techniques to generate cell values for these estimated parameters. Other SimSheet ${ }^{\mathrm{TM}}$ functions are used to tabulate and report results from the sample spreadsheets generated dynamically. The results for any cell in the spreadsheet can be summarized and statistics such as minimum, average and maximum reported. SimSheet ${ }^{\mathrm{TM}}$ output provides visibility of the best case, most likely and worst case results based on estimates of the uncertain variables affecting a decision. The full range of Excel functions are still available for analysis, summarizing and graphing the data. 


\section{Catania et al.}

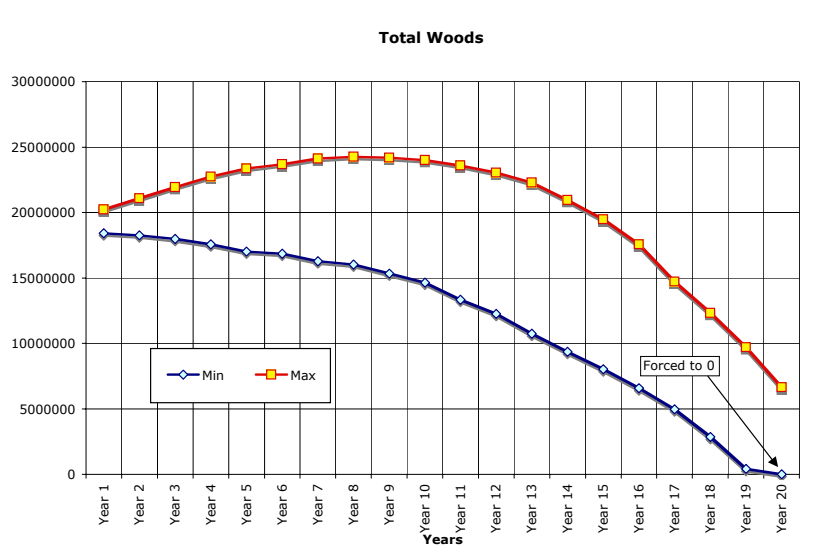

Figure 3: Simulated Total Woods Production

The implemented model was tested with 1000 replications, such number was identified in order to provide stability and variance reduction to the output measurements (as it is shown in the MSpE Time Evolution Analysis, figure 2), and the results are presented in figure 3-4-56-7.

\section{CONCLUSIONS}

Actual feasibility studies in the field of eco sustainability production are generally facing only some of the aspects of the problem. Power plants are considered separately from the territory in which are operating and the social impact of a new eco sustainable settlement is only roughly sketched. Resulting projects lack of a systematic view able to evaluate properly the long term effect of a new eco sustainable settlement on the social structure of a small rural town that is the typical target of any distributed energy production policy.

The proposed model results range from the population growth estimation to the evaluation of the wealth generated by the implementation of an eco sustainability power plants (i.e. energy consumption, energy generated) integrated with biomass based economy (i.e. yard production, sawmills revenues). Traditional ROI estimation can be obtained directly from the model showing the expected results in different scenarios (i.e. optimistic, pessimistic).

Looking at the simulation results appears clear that the model could be very useful in order to analyze in advance the potentials and the pitfalls of any integrated settlement not only limiting the investigation to the technical or economical details but also offers a broader view in which all the principal aspect (i.e social, economic, etc.) are accurately studied

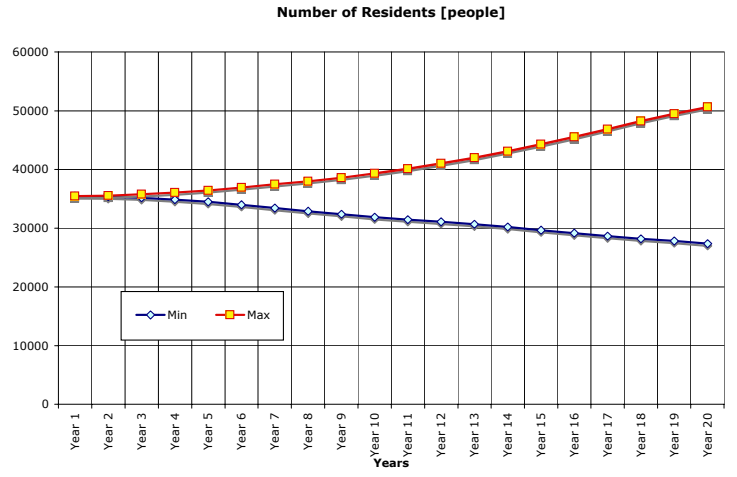

Figure 4: Simulated Total resident People

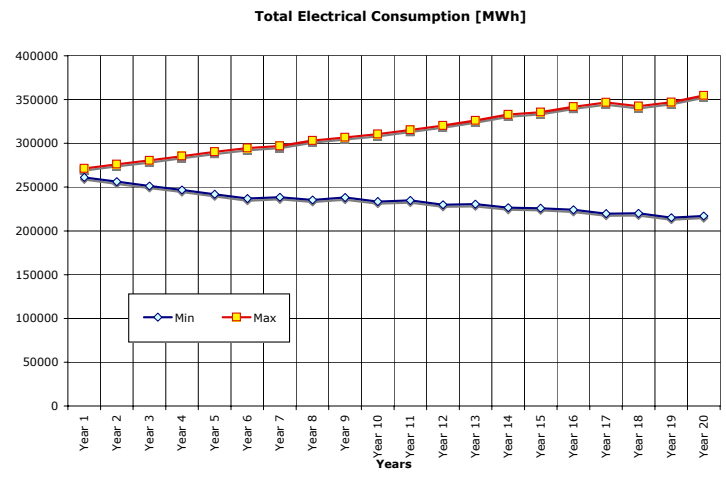

Figure 5: Simulated Total Electrical Consumption

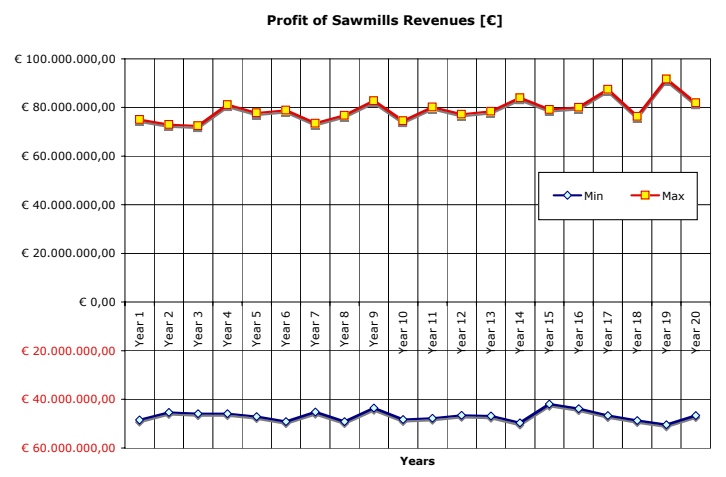

Figure 6: Simulated Sawmills Profit

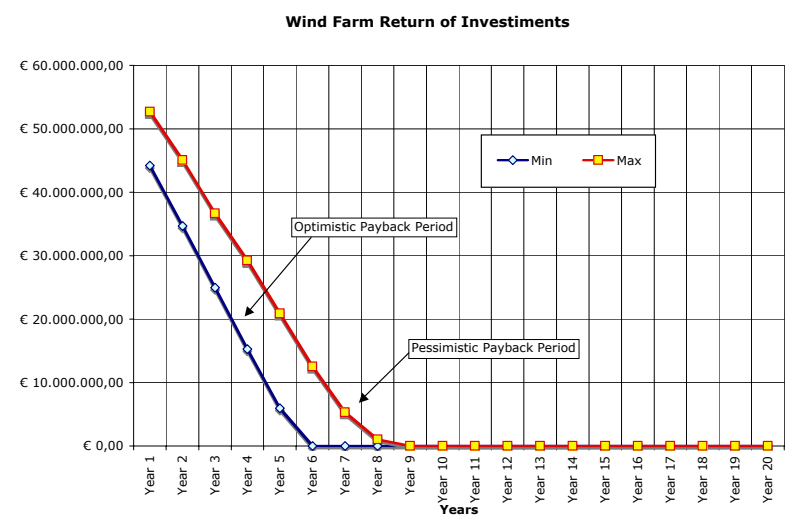

Figure 7: Wind Farm Payback Period Estimation 


\section{Catania et al.}

\section{ACKNOWLEDGEMENTS}

The authors thank M. Cagetti, S. Cipollina, M. Ferrara, M. Perucci for their support to this work.

\section{REFERENCES}

Anonymous. 1991. Introduction to Monte Carlo Method. The Computational Science Education Project, electronically available at: (last access May 2006) http://www.ipp.mpg.de/de/for/bereiche/stellarator/Co $\mathrm{mp} \_s c i / C o m p S c i e n c e / c s e p / c s e p 1 . p h y . o r n l . g o v / \mathrm{mc} / \mathrm{m}$ c.html

Anonymous. OSGI SimSheet Product Brochure. OSGI, Orlando FL electronically available at (last access May 2006) <http://www.osgi.com/simsheet.html $>$.

Banks, J., Carson, J., Nelson, B. 1996. Discrete-Event System Simulation, Second Edition, Prentice Hall

Bisoffi, S. 2000. Biomasse legnose da impianti a ciclo breve per la produzione di energia: sono una cosa seria? Sherwood 54, Ed. Compagnia delle Foreste,

Brun, F., Furlan, G. 2000. Studio dei costi di produzione e stima del prezzo minimo del cippato di legno per usi energetici. Relazione finale di ricerca, DEIAFA,.

Bruzzone, A.G., Giribone, P, Revetria, R. 1999. Design and Management Issues in the Development of New Workshops using Web-Based Simulation and Neural Networks. Proceedings of FAIM99, Tilburg (NL) June 23-25

Bruzzone, A.G., Mosca, R., Orsoni, A., Revetria, R. 2001. Forecasts Modelling in Industrial Applications Based on AI Techniques, International Journal of Computing Anticipatory Systems (extended from Proeedings of CASYS2001, Liege Belgium August 13-18), Vol 11, pp. 245-258, ISSN1373-5411

Corgnati, M. 1999. Valutazione tecnico-economica dello stato di attuazione delle iniziative di produzione di energia con biomasse forestali.

Executive Committee of IEA Bioenergy (EX CO 2002:03), Sustainable Production of woody biomass for energy.

Martinot, E. 2005. RENEWABLES - GLOBAL STATUS REPORT, Worldwatch Institute and GTZ GmbH

Mori, P. 2000. Stoccaggio contro biomasse? Sherwood, Ed. Compagnia delle Foreste.

Revetria, R., Figini, F., Sanguineti, M., Caballini, C. 2003. DIROMATIC: DIstRibuted Organizer, Manager \& AgenT Interactive Control, Proceedings of ICAMES, ENSO, Bogazici University, Istanbul, May.

Schlamadinger B. and G. Marland. 1996. The Role of Forest and Bioenergy Strategies in the Global Carbon Cycle, Biomass and Bioenergy 10: 5/6, 275-300.

Seila, Ceric, Tadikamalla. 2003. Applied simulation modelling. Duxbury Applied Series.
Wang L., Weller C. L., Hanna M. A. 2005. An Integrated Mathematical Model of Fluid Dynamics, Heat Transfer and Reaction Kinetics for Fluidized Bed Gasification of Biomass, Proceedings of The 2005 Annual Meeting (Cincinnati, OH)

\section{AUTHOR BIOGRAPHIES}

ROBERTO REVETRIA is Associate Professor in Mechanical Engineering and Logistics in the University of Genoa. He is consultant in several projects involving simulation with special attention to Distributed Discrete Event and Agent Based Continuous Simulation. He is teaching Modeling \& Simulation, VV\&A, Distributed Simulation (HLA), Project management in Master Courses Worldwide and he is teaching Industrial Plants Design, Maintenance Management in University of Genoa Masters' Courses. He is member of SCS, IASTED, ACM, ANIMP, AICE, MIMOS and LSC.

LUCIA CASSETTARI earned her degree in management engineering in 2004 at the University of Genoa . Currently she works in the Department of Production Engineering, and Mathematical Modelling (DIPTEM) at the University of Genoa as a researcher, in the field of simulator-based applications for industrial plants; particular attention is focused on the application of DOE and Optimization techniques to industrial plant problems using Simulation. She is also active in research projects involving BPR (Business Process Reengineering), Activity Based Management and Cost Control. She is senior lecturer in the Industrial Plant Management and Business Strategy degree courses.

FRANCESCA OLIVA earned her degree in management engineering in 2005 at the University of Genoa and she is studying for her $\mathrm{PhD}$ in Industrial Innovation Engineering at the University of Modena and Reggio Emilia.. Currently she works in the Department of Production Engineering, and Mathematical Modelling (DIPTEM) at the University of Genoa as a researcher, in the field of simulator-based applications for industrial plants and in the field of environmental analysis (Life Cycla Assessment). She is senior lecturer in the Industrial Plant Design degree courses.

ALESSANDRO CATANIA He has more than 21 years of working experience, he received his master degree in Social Sciences from Urbino University. He is working as consultant in the MindRevolver.com network as expert in Human Resources Management, Enterprise Resources Planning (ERP) and in work organization \& coordination.As responsible for founded industrial research problem is in touch with the Italian Ministero delle Attività Produttive as well with local Authority for Commerce \& 


\section{Catania et al.}

Trade, he was also responsible, in the last year, for more than $1.2 \mathrm{M} €$ in IT \& innovation technology projects. He was also involved as teacher in several professional seminars organized by local government agencies and private companies, in collaboration with the Department of Production Engineering \& Mathematical Models (DIPEM) of the Genoa's University he is responsible for project financing. 